\title{
Leadership Styles of Small Business Owners: Linking Theory to Application
}

\author{
Terry L. Howard \\ University of Detroit Mercy \\ Gregory W. Ulferts \\ University of Detroit Mercy \\ John Hannon \\ Walden University
}

To understand small business owners' management and leadership styles, an analytical examination of the different elements of the organization is useful. Although each owner manages a company differently, some fundamental principles are more successful, and yield higher opportunities for achievement, growth, and enhanced productivity over the long term. Business planning is vital. One essential step in planning is to develop a vision for the organization that conveys meaning. Effective management and leadership styles that promote an optimistic vision shared with all members of the organization, especially customers and the general community, yield a higher point of accomplishment for business owners.

\section{INTRODUCTION}

Small business ownership can be an enriching and lucrative experience for entrepreneurs of the 21st century. There are many exciting business opportunities for people who are prepared to learn through their experiences. Particularly rewarding are successes at all levels of the company's organization. Smoothly running a small business mandates a high level of knowledge about many critical factors of business organization: a) learning about business principles, b) best accounting practices, c) ethical guidelines and requirements, and d) legal regulations. Bamiatzi, Jones, Mitchelmore, and Nikolopoulos (2015) suggest that successful entrepreneurial leadership is increasingly becoming a basis of competitive advantage. Each topic requires mastery by the small business owner. There will be a discussion in this research paper of the observations as to how a small business owner might structure their thoughts relative to each critical factor. A significant limiting factor though is the limited leadership research conducted at the small business ownership level. As it pertains to management and leadership styles that would improve opportunities.

Within the context of the 21st-century global small to medium size enterprises (SMEs); there are many small business owners in a wide range of market sectors, educational backgrounds, and ethnicities. 
U.S.-based SMEs are composed of business owners that are widely diverse but have shared concerns and common goals. U.S.-based SME's are critical to national success. As Ayandibu and Houghton (2017) point out the SME sector contributes the most to employment in most countries. Though diverse there are many ways that small business owners could work collaboratively. Noteworthy are opportunities to leverage leadership techniques to ensure sustainable future sector growth. This area of research in the business organization has a high potential for improving the effectiveness of leadership for small business organizations in previously untapped ways. To date, most research studies in organizational management are within the framework of big business, with few efforts to learn about smaller firms (Sarkar, Wingreen, \& Cragg, 2017). Therefore, it is vital for small business owners to not only learn about, but participate in independent, but leadership topic based, research focused at the SME level.

\section{ECONOMIC FACTORS IN THE MANAGEMENT OF SMALL BUSINESS}

Traditionally, small business owners have always been a significant sector of the national community of business enterprise at nearly every level of economic progress, growth, and productivity. This fact applies in almost every nation and across all business enterprise sectors. Small businesses are comprised of so many different types of products and services, as well as being the basis of innovative technologies, mechanical products of various types - think, local hardware store - that it is challenging to pinpoint one specific kind of business approach that small business owners might have in common. Instead, these very enterprising individuals also have individual management approaches, at least as far as anyone yet has determined.

As previously mentioned, few research studies have focused on small business ownership -- also, the different entrepreneurial approaches to many sustainability issues and other modern concerns. Organizations often have limited resources to move forward on the larger projects, an issue that has been increasingly challenging for small business owners in the U.S. framework of bank lending. Ever since the economic crisis of, it has been more difficult for small business owners to find reasonably priced borrowing options. After the financial crisis of 2007-2009 banks announced they planned to reduce the number of loan set-asides to small business owners. True to their word, Simon (2015) reported that 10 of the largest banks issuing loans to small businesses lent $\$ 44.7$ billion in 2014, down 38\% from a peak of $\$ 72.5$ billion in 2006 , according to an analysis of the regulatory filings. However, small business owners are generally people who are more independent than most; they may prefer to continue to keep their small businesses going even when there are multiple economic downturns.

Some leadership styles which small business owners adapt during these problematic periods economically may not always encourage employees, who receive significant cuts in pay, work hours, and other limiting factors. Understanding small business owners and their management styles means following all of the ups and downs of small business enterprise, including the positive features of being one's boss; making choices about when to cut back on employee numbers, or expand the business beyond its normal parameters in the local community. Owning a small business means that there will be many opportunities to make money, but that too comes with risks.

While some people do become extraordinarily successful and wealthy as a result of a small business ownership idea, the more significant majority of small business owners are probably somewhere in the middle-income brackets when they achieve success. However, the SBE's that are not successful are high. Wagner (2013) reported that according to Bloomberg, 8 out of 10 start-up entrepreneurs fail within the first 18 months. Why are the failure rates so high? When an SBE entrepreneur first decides to work towards creating a small business enterprise, they are enthusiastic optimistic. So, why do so many give up their dreams about ownership of a small business so soon after they start? One reason may be the time required to obtain an acceptable return on the start-up funds invested. When outstanding loans generate that amount, the level of income often is insufficient to pay them back. Also, there may be family responsibilities or expenses that coincides with financial issues and require the SBE owner to moonlight at a steady-paying job. Another reason involves economic changes in the banking sector. Bank lending policies traditionally change with economic fluctuations. Such changes impact SBE owners 
disproportionately even though they may have excellent credit. In a downward economic cycle, small businesses are viewed by banks as poor credit risks.

Small business owners then must turn to even more risky borrowing options and risky move in lockstep with lending rates. Simon (2015) interviewed Rob Frohwein, chief executive of online lender Kabbage Inc., which charges on average 39\% rates. According to Frohwein, at least $60 \%$ of the borrowers with Kabbage, Inc. fell into traditional bank lending criteria. To address these financial concerns, some small businesses owners have created partnerships with bigger companies. For example, Lindberg (2016) reported that America Saves assisted supported local energy managers in establishing long-term relationships in the community in the difficult to access the small commercial market. These efforts helped the managers understand and realize the energy objectives of small business utility customers. These energy efficient programs had previously focused on big businesses in twelve different U.S. communities where America Saves operates.

\section{PRINCIPLES OF BUSINESS MANAGEMENT AND LEADERSHIP}

Economic policies that guide various processes in money management, consumer behaviors, and other critical points of ownership of a small business are especially important to understand. For the SBE organization to run smoothly, all organizational components must work together. To do so, the SBE owner must be grounded in proper management and leadership techniques. Academia created a large body of knowledge. A potential entrepreneur should consult this knowledge before embarking on a career as a small business owner. When reviewed in advance this body of management and leadership knowledge will provide a robust framework for the upstart SBE that will provide a robust basis for understanding inner organizational workings and thus provide the new business owner a clear path to success.

While knowing management and leadership essentials are critical to a successful business, a more critical factor is the way that company owners apply those skill sets. When adequately chosen the proper leadership styles will provide the small business owner with a framework to achieve SBE success.

Understanding how different leadership styles work within the structural framework of business organizations to improve success overall is an essential area of a research study that brings a higher level of knowledge for small business enterprises of the 21 st century. The first step in this process of understanding the studies requires learning about how researchers define the necessary qualities of leadership. Fortunately, there is plenty of quite informative research material available that describe the conditions of effective 21 st-century leaders. In small business organizations, managing leadership style plays a vital role in company success as it does for larger business enterprises.

For example, the leadership awareness of one of the largest successful organizations in the world today, Disney, applies equally to the leadership styles of small business owners. For example, the worldwide success of the Disney Company, one of the largest organizations in the world today, we will discuss further in the paper in detail. The point to be made here is that many of the principles of the Disney Company's success also can apply to the leadership styles of small business owners.

Large or small, certain similarities among successful business enterprises seem to share a few specific characteristics in common, and the value of effective leadership is one of these main shared points. Henry, Foss, Fayolle, Walker, and Duffy (2015) describe entrepreneurial leadership as the dynamic process of framing a vision, obligating followers and risk acceptance when embracing opportunities that utilize available resources. As a starting point for this research study, this definition provides a concise yet understandable focus on what some of the most critical aspects of leadership may be. These definable objectives have significant areas of focused awareness for many people and organizations in the $21 \mathrm{st}$ century. In many ways, they provide a sense of purpose as well as a better understanding of how and why leadership styles have become such an integral component of building small business ownership teams.

These approaches to business are not essential for running a business in the same way as understanding financial principles are, yet they may even be more critical for the success of the company in the long term. For these reasons, a close analytical view of the various aspects of small business owners 
and their leadership styles continues to be one of the most important and well-researched areas of organizational management and behaviors.

As many people will readily recognize just as a matter of personal observation, managing a company is different for each owner; there are many individual aspects of owning a small business operation that show these differences outwardly. Small business owners who run restaurants are a striking example of the different management styles of each company, even though they are all selling the same product-in the case of restaurant ownership, food. However, every restaurant along the same block or in the same community will have a completely different approach and style that they also are sharing with their customers, in addition to the variation in the actual food itself. This example is one of many that points out how small business owners each reflect their unique personalities by way of their products, services, and generally in every aspect of business ownership that includes a particular leadership style as well.

Even though this example shows why it is well-established that every small business owner is unique, there are basic principles that are considered to be most effective and that lead to higher opportunities for success, growth, and increased productivity over the long term.

Small business owners from various market sectors have many different ways that they conduct the business organizations of their companies. Entrepreneurs are often very creative and distinctive in their approaches to business, which applies to the products and services offered, the vision of their small business enterprise, and every other aspect of the organization as a whole. Each unique company will be significantly shaped and affected by these organizational management tasks, which are crucial for the success of the organization. It is especially important to understand the management and leadership styles of small business owners from an analytic perspective. Turner and Endres (2017) noted that in according to the U.S. Small Business Administration report in 2016, 99.9\% of all firms in the United States are small business owners, employing $48 \%$ of the employees in the private sector, and providing $41.2 \%$ of the payroll in the total U.S. private sector. This statistical data highlights the significant position of small business ownership within the U.S. economy that also addresses the vast diversity and range of these companies. Whether they are in the business of selling highly profitable and sought-after products and services such as designer clothes and shoes or are primarily selling soft drinks on the corner neighborhood market, all of these businesses will be affected by the management and leadership styles of their particular owners.

Organized business planning is essential for achieving these objectives because it provides small business owners with a framework for moving forward in a direction that is positive. One of the first, most essential steps in this planning process is to develop a vision for the company that brings meaning to the very core of the business organization.

Effective management and leadership styles encourage a shared vision that includes clients and the general public in a positive manner. Bring a higher level of success for small business owners. While no one business will be exactly like another in their leadership styles, there are a few basic principles that may apply to every small business.

These areas of research are in this study from a general position of analysis, mainly as a positive way to learn about some of the most effective business practices of the 21st century. Turner and Endres (2017) point out that small businesses account for a significant part of the U.S. job creation in the United States and fuels the economy despite failing at alarming rates. Among other possibilities, some of these small business failures may be an indication that there are some issues in management and leadership styles. In some cases, there may be some problematic issues with the organizational management of the company at any level, which could be related to the financial and accounting areas of business enterprise systems. These areas of concern may all be very complicated, which is an essential reason for hiring professional accountants, financial analysts, and other specialized experts in the field of money management. These areas of ownership of a small business are frequently quite flexible, in that the company owner-managers will often keep track of the accounts without hiring a financial consultant. However, since this area of business is so vitally important to the long-range success of the company, including all of the areas of tax assets and liabilities and other tax-related concerns, most business professionals will recommend 
professional counselors on tax matters to assure the highest level of proficiency for the company's financial health overall.

Organizational behavior management research groups small business into a category, known as small and medium-sized enterprises (SMEs). SMEs are an essential group of various companies, primarily in the private sector, which is very important for maintaining a robust economy is moving forward in a positive direction of growth and productivity. De Oliveira, Escrivão, Nagano, Ferraudo, and Rosim (2015) note that various titles are used to describe the top SME positions depending on their traits in the interests of the company: owner, manager, entrepreneur, entrepreneur-owner, entrepreneur-manager, and owner-manager. It is not actually as complicated as these lengthy hyphenated names suggest; basically, these different labels may refer to who is paying for certain aspects of the company (generally, the owner); who comes up with new, innovative ideas (typically, the entrepreneur); and who actually runs the everyday operations of the company (generally, the manager). When there are combinations of the three aspects of small business ownership, this factor signifies a more involved role in all three areas of the business, which also occurs frequently in SMEs.

Today, according to Adams, Keloharju, and Knüpfer (2017), there has been a high level of interest focusing on research that can successfully identify leader traits, especially business leaders. Small business organizations may not always need a Chief Executive Officer (CEO) other than the company owner, especially during the first couple of months or even years that the business is operational. Instead, there may be a variety of multi-tasking or designating specific organizational roles to different people in the business-this common aspect of the early business organization is where the expression of wearing many hats originates - that is, one person will perform many different roles that are essential for successful business operations. In recent years, the many advances in business technologies as well as in technological society in its entirety caused significant changes in the organization of small businesses.

These changes connect to many sociopolitical, cultural, and human conditions of the 21 st-century environment as it pertains to society and the economy in general; that is, the businesses of our grandparents, for example, would be unrecognizable to people just starting in the business world today. Not only are the technological tools completely different - think manual typewriter versus laptop computer or iPad - but also the different ways that small business owners think about their organizational tasks and skills. Owners are more likely to include the global community in the 21 st century, wherein past generations the local communities and neighborhood grocery stores were about as far as most small business owners would venture out to find a solid customer base.

These uniquely different business settings also have changed some of the managerial tasks of small business operations, according to recent research on this topic. According to de Oliveir et al. (2015), many researchers have written about transformations in the organizational environment, in labor and also in the competitive market, consequently resulting in considerable changes in the managerial work. The importance of business management organization is still every bit as important for the overall success and growth of the company as it was in generations past, a time before there were computers that performed nearly every mathematical task for business owners. The history of technology as it pertains to modern business times dates back hundreds of years, at least to the printing press invention in the 15th century (McNeil, 2002). New technologies and devices have been evolving along with human civilizations for centuries; they are nothing new. However, what is new in the 21 st century is the rapidly advancing technologies that are shaping organizations in a different way than businesses of the past. Examples are everywhere, from using our smartphones to order food at the local McDonald's before we get there, to shopping online for items that would generally be easier to pick up at the local market in the past.

All of these organizational methods and technologies that are changing how consumers shop -in fact, already replaced them, especially in urban areas where technology is as advanced and up-to-date. Innovative advancements also mean that leadership styles of small business owners all will need to be able to adapt; to be more flexible as managers within the business organization for people in the company also to be able to adjust within 21st-century business environments. Bock, Opsahl, George, and Gann (2012) point out that organizational leaders aspire to achieve strategic agility, which is the ability to identify innovative opportunities, commit resources to new endeavors, or reverse deployment of 
underutilized resources. There are just many significant changes to the business organization and management skills, which are changing almost daily as computers have assumed an increasingly central position in nearly every small business organization today. Academic researchers such as Gemser, Brand, and Sorge (2004) in business labeled these differences as typically "old economy' (i.e., mechanical engineering) and 'new economy' (i.e., computer software)." This distinction may seem to point out the obvious - that the digital age has almost entirely replaced old technologies. Some people and organizations have not kept up with advances in technology.

Not every person is adept at how to run complex business analyst systems that have been designed by a computer programmer to save time on accounting management tasks. Nor are they always older people who are not using the complex programs, although there is somewhat of a severe generational divide that has been over-rated in many news reports. According to Neves, Franz, Munteanu, Baecker, and Ngo (2015), older people are using computer technologies more than ever before in many innovative waysincluding what sociologists have labeled the "oldest old." There may be other reasons why some small business owners shy away from technologies at the most advanced levels of their organizational management practices. Perhaps privacy issues are a concern, which is still an important area of technology that has not been fully resolved even yet, as the daily news reports about various breaches of security due to computer technology factors seem to confirm (Pleshakova, 2018). It is critical for business owners to keep up with these technological advances or hire someone knowledgeable to do so as soon as possible. Segal (2018) notes that technology is critical for any business to operate efficiently and effectively and requires that the owner must keep up with current trends that will help your business. Otherwise, the business organization will meet with challenges that may be overwhelming.

In the 21 st century, there are many opportunities for keeping up with the computer technologies that do not require expert computer programming knowledge; they may often be challenging, but they are generally straightforward and significant for any small business enterprise that is going to remain relevant for the future. Segal (2018) points out that currency with technology helps prepare your business for the changing demands and expectations of customers. Segal states that staying on top of these trends will increase the owner's relevancy and customer demand, providing distinctive differences from the competition. For example, there are hundreds of ways today to be able to keep track of what consumers are interested in buying, and conversely which products they will reject in favor of another, more relevant and up-to-date product. This area of marketing research is perhaps one of the essential early strategies that a small business owner can do: to make sure that his or her products will be successful in finding a strong marketing niche. The way that consumers today do almost all of their shopping online, a trend that is likely to continue in even stronger waves of interest as the 21 st century progresses, all indicate the importance of exploring what is known today as digital user practices (Kormelink \& Meijer, 2017).

There are many reasons why anyone who is going to start their own business should be fully knowledgeable and educated about every aspect of the business organization, not just one area of expertise. The ability to perform a variety of jobs is a precious one, and almost mandatory for small business ownership. The importance of expert market research analysis is an area of concern for many new small business owners. Yates (2018) estimated that approximately $10 \%$ of all start-ups continue to exist and succeed. Many things can cause this result, but best wisdom suggests that it may be due to a lack of market research. Yates found that $42 \%$ of start-up owners said there was no demand for the product or service they offered. This multi-tasking approach is becoming increasingly necessary for small business owners as the 21 st century progresses.

\section{LEADERSHIP SKILLS AND INNOVATION IN THE $21^{\text {st }}$ CENTURY}

Another critical area for small business owners and leaders to recognize is the high position of new innovative technologies and other innovations as one of the vital components of keeping a business relevant in the business world enterprises of the 21st century. According to Dunne, Aaron, McDowell, Urban, and Geho (2016), it is well-known among researchers for business organizations that a firm's innovative ability often determines its success. 
Entrepreneurial studies provide the theoretical context and background research for improving the ways that new companies, especially SMEs, are adjusting to many of the changes of the 21 st century. Karadag (2015) noted that SMEs are the drivers of socio-economic growth for most economies. In many ways, these changes are more closely related to sociocultural advances based on a different economic, organizational structure at several different levels. The reference to developing economies is one that has many serious implications such as issues about sustainability, wage contracts between governmental organizations that sometimes are very different culturally, and many other factors that all need consideration from a sociocultural and ethical perspective. Thus, in today's intricately connected global economies, with many increased opportunities as well as challenges, all of these factors have an essential role in small business management and leadership styles.

Academic researchers and business planners alike note these issues have as some of the most critical concerns for business owners of the 21st century. Franco and Matos (2015) state that understanding leadership is fundamentally significant not only for the business itself but also for its environment since any SME is emersed in a social, economic and environmental framework. Policy decision-makers need to include land evaluations, environmental impact studies, and many other sociocultural and environmental factors before they move into a particular area. Addressing these intersecting concerns will be beneficially for all of the key stakeholders,

These ethical concerns also include, and are especially important, for the local communities who are affected by any SMEs that have landed close to where they live; and, in some unfortunate cases, may even displace them. These environmental factors are significant issues, referring to sustainable development where small business owners need to be very aware of their impact on local communities and the like. Not every business will be moving to an internationally undeveloped region somewhere in the world. Once considered remote and out of reach, there are a significant amount of companies that do plan expansion, which is a common practice according to Franco and Matos (2015) in the modern business environment characterized by worldwide markets, global competitive forces, ongoing technology advances, and continuous innovation framed with other political and social factors.

\section{THE FUTURE OF SMALL BUSINESS OWNERSHIP}

As these studies and more have clearly shown, ownership of a small business in the 21 st century is a rapidly-evolving, dynamic, and sometimes unpredictable experience for the business owners who have shaped a vision for their ideas into a small business enterprise. Some statistics highlight the risks involved. Estimates are that up to $80 \%$ of small businesses may fail within the first 18 months (Wagner, 2013). Some people who may have big dreams to sustain them through the difficult early times of any business enterprise. They are the people who also inspire others. These entrepreneurs are not only role models for small business owners of the future; they also are the leaders in innovative technology and other essential businesses, large or small.

For anyone who has ever been a visitor at one of the Disney parks now situated in various locations around the globe, it may seem hard to believe that Walt Disney once had limited financial resources to work with for his small business enterprise. However, in all truth, the Disney story is one of great hardship that moved into a great success. The success occurred because Walt Disney in his youth did not even imagine that failure was an option; instead, he only pursued what he was inspired to work on, beginning with his cartoon characters such as Mickey Mouse, Donald Duck, Goofy, and others who are now recognized by millions of people all around the world.

It is often the case at the Disney resorts today that the Disney magic still will be in view for the many children who now visit the parks. What many people do not know, however, is that there are several unique small businesses nestled within the Disney parks that also have been fortunate enough to experience such a high level of financial success. Even though to the outside world the Disney corporation may seem like some giant monolithic entity that is only interested in becoming wealthier and more powerful as a media giant, in actuality the Disney experience is still very quaint. The focus is most importantly on the quality of experiences that guests will have, and possibly even remember for the rest of 
their lives. Thus, the Disney style of leadership has been held up by many business organizations as a positive, also transforming way to build up one's customer base using excellent guest service and many other unique interactions that Disney employees are all taught to follow, with generally positive results. This factor is due to another, perhaps lesser-known but true story-most people who work at the Disney parks are more interested in spending time there than in making money; generally young students employed part-time, they will not be getting rich by working there, but they will be experiencing something more precious than money-happiness. The generally happy atmosphere that permeates all of the Disney Parks, but uniquely the original in Anaheim, California, is the Disney style of leadership that Walt Disney promoted from the very first day Disneyland opened in 1955. Walt Disney proclaimed that Disneyland was going to be "The Happiest Place on Earth," and in many ways, his prediction still has a resonance that continues to bring joy and happiness to visitors numbering in the millions on an annual basis.

For example, as one interaction at a Disney Park was explained by an observer by Isabella, Yemen, Isabella, and Yemen (2017) between a young Animal Kingdom Lodge guest and an employee where the exchange could have been different, yet the experience was magical for the youngster. There is little doubt that Walt Disney would not have been surprised. For purposes of this study, the main reason I have used this anecdotal story is to point out the central importance of Walt Disney, as he is still fondly remembered over fifty years after his passing in 1966. This long remembrance is not only a testament to how it is to demonstrate the long-range effects of a true leader such as Walt Disney was in his lifetime.

\section{CONCLUSION}

Small business owners have a variety of approaches and styles that are very important to the uniqueness of each entrepreneurial enterprise. In the 21 st century, there are many increased opportunities for building up a small business with a minimum of stress and a higher chance of success. According to some research studies, many small business leaders are becoming more closely involved with the organization of every aspect of the business. Simsek, Jansen, Minichilli, and Escriba-Esteve (2015) suggest that because emerging ventures have fewer levels of hierarchy, their owners tend to be essential to the firm's strategic, tactical, and even operating core. This exciting development means that small business owners also will have a more influential role in the buildup of their companies from the very beginning - much like Walt Disney when he first began to develop his visionary role as an originator of amusement theme parks. When a person is going to dream about opening up a small business enterprise, he or she will do right by that dream by believing in success even against the odds. As a primary leadership style that is known to be highly effective in promoting a positive work environment, having a positive attitude may be one of the very most important factors in leading a small business enterprise towards long-term success.

\section{REFERENCES}

Adams, R. B., Keloharju, M., \& Knüpfer, S. (2017). Are CEOs born leaders? Lessons from traits of a million individuals. Harvard Business School Research Paper No. 16-044.

Ayandibu, A. O., \& Houghton, J. (2017). The role of Small and Medium Scale Enterprise in local economic development (LED). Journal of Business and Retail Management Research (JBRMR), 11(2), 133-139.

Bamiatzi, V., Jones, S., Mitchelmore, S., \& Nikolopoulos, K. (2015). The role of competencies in shaping the leadership style of female entrepreneurs: The case of North West of England, Yorkshire, and North Wales. Journal of Small Business Management, 53(3), 627-644.

Bock, A. J., Opsahl, T., George, G., \& Gann, D. M. (2012). The effects of culture and structure on strategic flexibility during business model innovation. Journal of Management Studies, 49(2), 279-305. 
de Oliveira, J., Escrivão, E., Nagano, M. S., Ferraudo, A. S., \& Rosim, D. (2015). What do small business owner-managers do? A managerial work perspective. Journal of Global Entrepreneurship Research, 5(1), 1-21.

Dunne, T. C., Aaron, J. R., McDowell, W. C., Urban, D. J., \& Geho, P. R. (2016). The impact of leadership on small business innovativeness. Journal of Business Research, 69(11), 4876-4881.

Franco, M., \& Matos, P. G. (2015). Leadership styles in SMEs: a mixed-method approach. International Entrepreneurship and Management Journal, 11(2), 425-451.

Gemser, G., Brand, M. J., \& Sorge, A. (2004). Exploring the internationalisation process of small businesses: a study of Dutch old and new economy firms. MIR: Management International Review, 127-150.

Henry, C., Foss, L., Fayolle, A., Walker, E., \& Duffy, S. (2015). Entrepreneurial leadership and gender: Exploring theory and practice in global contexts. Journal of Small Business Management, 53(3), 581-586.

Isabella, L. A., Yemen, G., Isabella, L. A., \& Yemen, G. (2017). The wonderful world of human resources at Disney. Darden Business Publishing Cases, 1-14.

Karadag, H. (2015). Financial management challenges in small and medium-sized enterprises: A strategic management approach. Emerging Markets Journal, 5(1), 26-40.

Kormelink, T. G., \& Meijer, I. C. (2017). What clicks actually mean: Exploring digital news user practices. Journalism, 1464884916688290.

Lindberg, J. (2016). America Saves! Energizing Main Street's small businesses (No. DOE-NTHP-EE0006291). National Trust for Historic Preservation, Washington, DC (United States).

McNeil, I. (Ed.). (2002). An encyclopedia of the history of technology. Routledge.

Neves, B. B., Franz, R. L., Munteanu, C., Baecker, R., \& Ngo, M. (2015, April). My hand doesn't listen to me!: Adoption and evaluation of a communication technology for the 'oldest old.' In Proceedings of the 33rd Annual ACM Conference on Human Factors in Computing Systems (pp. 1593-1602). ACM.

Pleshakova, A. (2018). Data breach report: April 2018. Nehemiahsecurity.com. Retrieved June 14, 2018, from https://nehemiahsecurity.com/blog/breach-report-april-2018/

Sarkar, A., Wingreen, S. C., \& Cragg, P. (2017). CEO Decision Making under Crisis: An Agency Theory Perspective. Pacific Asia Journal of the Association for Information Systems, 9(2), 1-21.

Segal, C. (2018). How your business can keep up with changing technology trends. Coxblue.com. Retrieved June 14, 2018, from http://www.coxblue.com/how-your-business-can-keep-up-withchanging-technology-trends/

Simon, R. (2015, Nov. 26). Big banks cut back on loans to small business. Wall Street Journal. Retrieved June 10, 1018, from https://www.wsj.com/articles/big-banks-cut-back-on-small-business1448586637.

Simsek, Z., Jansen, J. J., Minichilli, A., \& Escriba-Esteve, A. (2015). Strategic leadership and leaders in entrepreneurial contexts: A nexus for innovation and impact missed? Journal of Management Studies, 52(4), 463-478.

Turner, S., \& Endres, A. (2017). Strategies for Enhancing Small Business Owners' Success Rates. International Journal of Applied Management and Technology, 16(1), 34-49.

Wagner, E. (2013). Five reasons 8 out of 10 businesses fail. Forbes.com. Retrieved June 14, 2018, from https://www.forbes.com/sites/ericwagner/2013/09/12/five-reasons-8-out-of-10-businessesfail/\#5658e2a16978

Yates, L. (2018). 4 interesting facts about startups every entrepreneur should know. SDGbusiness forum.com. Retrieved June 14, 2018, from http://sdgbusinessforum.com/sessions.html 